\title{
A Real-World Observational Study Examining the Impact of Aclidinium Bromide Therapy on the Quality of Life, Symptoms, and Activity Impairment of Patients with Chronic Obstructive Pulmonary Disease: The Greek ON-AIR Study
}

This article was published in the following Dove Press journal: International Journal of Chronic Obstructive Pulmonary Disease

\section{Konstantinos Kostikas, (D) Theodoros I Vassilakopoulos, 2,3 Nikos Tzanakis, ${ }^{4}$ Athanasios K Konstantinidis, (D) ' Epameinondas N Kosmas, ${ }^{5}$ Spyros Papiris, 6 Paschalis Steiropoulos, (iD) ${ }^{7}$ Effrosyni D Manali, ${ }^{6}$ Stylianos A Michaelides, ${ }^{8, \dagger}$ Grigorios Daskos (D) ${ }^{9}$ \\ 'Respiratory Medicine Department, University Hospital of loannina, loannina, Greece; ${ }^{2}$ Pulmonary and Critical Care Medicine, Medical School, National and Kapodistrian University of Athens, Athens, Greece; ${ }^{3}$ Third Department of Critical Care Medicine, Evgenideio Hospital, Medical School, National and Kapodistrian University of Athens, Athens, Greece; ${ }^{4}$ Department of Respiratory Medicine, University Hospital of Heraklion, Medical School, University of Crete, Crete, Greece; ${ }^{5}$ Department of Pulmonary Medicine, Metropolitan Hospital, Athens, Greece; ' ${ }^{6}$ Second Pulmonary Medicine Department, General University Hospital "Attikon", Medical School, National and Kapodistrian University of Athens, Athens, Greece; ${ }^{7}$ Pulmonology Clinic Medical School, Democritus University of Thrace/University General Hospital, Alexandroupolis, Greece; ${ }^{8}$ Department of Occupational Lung Disease and Tuberculosis, "Sismanogleio-Amalia Fleming" General Hospital, Athens, Greece; 'MENARINI HELLAS, Athens, Greece}

tStylianos A Michaelides passed away on September 14, 2019

Correspondence: Konstantinos Kostikas Respiratory Medicine Department, University of loannina School of Medicine, Leoforos Stavrou Niarchou, loannina 45500, Greece

Tel +30-265l007536

Email ktkostikas@gmail.com
Purpose: This multicenter, prospective, observational study aimed to supplement real-world evidence on the effects of aclidinium bromide on the quality of life (QoL), symptoms, and activity impairment of patients with COPD.

Patients and Methods: Eligible patients were $\geq 40$ years of age, newly initiated on aclidinium bromide as monotherapy or add-on therapy according to the product's approved label. Patient-reported COPD assessment test (CAT), the severity of symptoms and their impact on daily activities, and the features of the Genuair ${ }^{\circledR}$ inhaler device were assessed at enrollment and at 12 weeks post-treatment onset.

Results: Between 13 March 2015 and 29 January 2016, 285 eligible consenting patients (76.3\% males; median age: 69.0 years; $26.0 \%$ newly diagnosed with COPD) were enrolled by 15 hospital-based respiratory medicine specialists in Greece. Aclidinium bromide was initiated as add-on therapy to other inhaled maintenance medications in $73.1 \%$ of evaluable patients. The median (interquartile range [IQR]) baseline CAT score decreased from 14.0 $(9.0-20.0)$ to $10.0(6.0-15.0)$ points $(\mathrm{p}<0.001)$ after 12 weeks of treatment, with $76.5 \%$ of the patients achieving $\mathrm{a} \geq 2$-point decrease. The severity of night-time and early-morning symptoms, assessed using a 5-point Likert-type scale, decreased from a median (IQR) of 1.0 $(0.0-2.0)$ to $0.0(0.0-1.0)$, and from $2.0(1.0-2.0)$ to $1.0(1.0-2.0)$, respectively $(\mathrm{p}<0.001$ for both). In patients with paired data, the prevalence of at least moderate night-time symptoms, early-morning symptoms, and daily activity impairment decreased from $28.2 \%$ to $19.1 \%$, from $63.6 \%$ to $34.2 \%$, and from $59.5 \%$ to $38.7 \%$, respectively ( $<<0.001$ for all). Inhaler device features were assessed as "very good"/“good" by more than $90 \%$ of the patients. The adverse drug reaction rate was $1.4 \%$.

Conclusion: The study provides real-world evidence on the beneficial effects of aclidinium bromide on the patients' QoL, symptom severity, and daily activity impairment, which are complemented by a favorable safety profile and high patient satisfaction with the inhaler device. Keywords: aclidinium, chronic obstructive pulmonary disease, COPD assessment test, daily activities, quality of life, symptoms

\section{Introduction}

Chronic obstructive pulmonary disease (COPD) is characterized by persistent respiratory symptoms and airflow limitation, and is associated with quality of life 
(QoL) impairments and substantial economic and social burden. ${ }^{1-3}$ In 2017 COPD ranked as the fifth leading cause of death and the seventh cause of disability in Greece ${ }^{4}$ and is predicted to be the fourth leading cause of death and the fifth cause of disability worldwide in $20300^{3}$

Dyspnea, cough, and sputum production are the cardinal symptoms of COPD. ${ }^{5}$ Symptomatology varies throughout the day, with most patients reporting worse COPD symptoms during the early-morning followed by those at nighttime, leading to limitations in performing morning activities and to night-time awakenings, respectively. ${ }^{5-8}$ According to the 2019 Global Initiative for Chronic Obstructive Lung Disease (GOLD) consensus guidelines, the level of the patients' symptoms and exacerbations should be at the epicenter of both initial and follow-up pharmacological treatment decision-making. ${ }^{9}$ Specifically, initial pharmacotherapy decisions should be based on a combined assessment approach (ABCD classification), which takes into consideration the assessment of the patient's symptom burden [via the Medical Research Council questionnaire or the COPD Assessment Test (CAT)] and the history of exacerbations. ${ }^{9}$ Reducing symptoms in conjunction with improving the health status and reducing the risk for exacerbations, disease progression, and mortality represent the major goals for the treatment of stable COPD.

Long-acting muscarinic antagonists (LAMA) are recommended as initial therapy for patients across all GOLD ABCD Groups, and together with long-acting $\beta$ agonists (LABA) and inhaled corticosteroids (ICS) comprise the mainstay inhaled maintenance COPD treatments. ${ }^{9}$ Aclidinium bromide, an approved LAMA for adult patients with stable COPD, has a rapid onset of action and high selectivity for M3 muscarinic receptors leading to airway smooth muscle relaxation. In addition, aclidinium has a shorter half-life than tiotropium and is rapidly hydrolyzed in the plasma, attributes that limit its systemic adverse events. ${ }^{5}$ To date, in Europe, it is the only LAMA that can be dosed twice a day. ${ }^{5,10}$ The inhalation device of aclidinium bromide is equipped with a safety mechanism to prevent accidental double-dosing, a dose indicator, feedback mechanism for correct inhalation, and a lockout mechanism. The features of the device have been linked with fewer inhalation errors and high patient satisfaction. ${ }^{11,12}$

The efficacy of aclidinium bromide in reducing exacerbations and improving lung function has been demonstrated in randomized placebo-controlled trials. ${ }^{13-17}$ In a phase IIIb trial including moderate-to-severe COPD patients who were randomized to aclidinium, tiotropium, or placebo for 6 weeks, aclidinium demonstrated significant improvements compared to placebo in reducing the presence and severity of early-morning and night-time symptoms, and in improving activity limitation due to COPD symptoms. ${ }^{18}$

Real-world evidence regarding the beneficial effect of aclidinium bromide on the symptoms and QoL of patients with COPD treated in routine care settings is gradually emerging. ${ }^{19-21}$ In view of the scarcity of published real-life data at the time of study planning, the Greek ON-AIR study aimed to supplement the evidence by hypothesizing that aclidinium bromide has beneficial effects on the QoL of the patients, the presence and severity of early-morning and night-time COPD symptoms, and the patient-perceived impact of COPD symptoms on their daily activities. It also aimed to capture the patients' and physicians' perspectives of the inhaler device features and collect data regarding the safety of aclidinium when used in accordance with the approved label in routine care settings in Greece.

\section{Patients and Methods Study Design and Setting}

This was an observational, multicenter study conducted in 15 hospital pulmonary clinics in Greece. Patients with COPD were consecutively enrolled between 13-March-2015 and 29-January-2016 by respiratory medicine specialists. The study was conducted in accordance with the International Society for Pharmacoepidemiology guidelines for Good Pharmacoepidemiology Practice, ${ }^{22}$ the ethical principles of the Declaration of Helsinki, and all standing regulations. The study protocol and informed consent form were reviewed and approved by all Institutional Review Boards (Scientific Council and/or Board of Directors) of the participating hospital sites before the enrollment of any patient in the study and performance of any study-related procedures. Signed informed consent was obtained from all patients.

Patients were treated with aclidinium bromide for a period of 3 months (12 weeks), according to the summary of product characteristics (SmPC) and the patient's therapeutic needs. The decision to prescribe aclidinium bromide therapy was taken prior to their enrollment in the study and was clearly separated from the physician's decision to include the patient in the study. Management and monitoring of the patient were carried out according to standard medical practice. Data were collected at enrollment and at a second visit that occurred approximately 12 weeks post-enrollment (follow-up visit) and were documented on paper Case Report Forms. 


\section{Study Population and Study Medication}

The study included both male and female patients, aged $\geq 40$ years, with an established COPD diagnosis, who were newly initiated on treatment with aclidinium bromide inhalation powder (Bretaris ${ }^{\circledR}$ Genuair $^{\circledR}$ ) at the recommended dose of one inhalation of $322-\mu \mathrm{g}$ aclidinium twice daily (either as initial therapy, as change to the current treatment, or as addon therapy, according to the physician's judgment), were able and willing to comply with the study procedures, and who provided written informed consent prior to enrollment. Patients with any contraindication to the use of anticholinergics in accordance with the SmPC or hypersensitivity to aclidinium bromide, atropine, or its derivatives, as well as pregnant or lactating women, were excluded from study participation.

\section{Assessments}

Disease-related QoL was assessed using the Greek version of the CAT, which was completed by the patients at enrollment and at the 12-week follow-up visit. At both visits, physicians assessed the presence and severity of the patient-reported night-time and early-morning symptoms using a 5-point Likert-type scale ${ }^{23}$ (ranging from "no symptoms" to "very severe symptoms"). Moreover, at both visits, patients were asked to indicate their most troublesome early-morning symptoms (cough, difficulty in breathing, wheezing/breath sounds, and difficulty in clearing mucus) and to rate the severity on a 4-point Likert-type scale (ranging from "mild" to "very severe"). In addition, patients were asked to indicate the extent to which their COPD symptoms had an impact on their daily activities using a 5-point Likert-type scale (ranging from "not at all", to "a very large extent") and the frequency of their nocturnal awakenings. At the follow-up visit, both physicians and patients were asked to evaluate the features of the inhaler device on a 4-point Likert-type scale (very good, good, neutral, bad) and to indicate their willingness to continue treatment with the prescribed inhaler. Throughout the study observation period, the occurrence of adverse events regardless of their causal relationship with the study medication were monitored, recorded, and reported.

\section{Statistical Analysis}

The normality of distribution of continuous variables was assessed using the Shapiro-Wilk test. The statistical significance of changes of continuous variables [CAT score and symptom severity (using a 5-point scale, with 0 corresponding to "no symptoms" and 4 to "very severe symptoms")] between enrollment and the follow-up visit were evaluated using the Wilcoxon signed-rank test. Changes from enrollment to the follow-up visit in the proportion of patients with and without nocturnal awakenings, with and without night-time and early morning symptoms of at least moderate severity, and with and without at least moderate impairment of daily activities were assessed with the McNemar test. The impact of patient, treatment, and disease characteristics on achievement of the minimum clinically important difference (MCID; defined as a decrease of 2 or more units from enrollment to the follow-up visit $)^{24}$ in the total CAT score at the follow-up visit was evaluated using logistic regression models. The multivariable logistic regression model was derived using a stepwise procedure based on the minimization of the Akaike's Information Criterion ${ }^{25}$ and included the following baseline variables in the initial stepwise procedure: sex, age category, obesity [body mass index (BMI) $\geq 30 \mathrm{~kg} / \mathrm{m}^{2}$ ], smoking status, new COPD diagnosis, cardiac/vascular disorders, metabolism/nutrition disorders, comorbidity count, CAT total score at enrollment, no prior LAMA, initiation of aclidinium bromide as add-on therapy with other inhaled maintenance therapy, and at least moderate early-morning and/ or night-time symptoms. In addition, univariable linear regression models were fitted in order to evaluate the impact of factors of interest on the change of the CAT total score from enrollment to the post-enrollment visit All statistical tests were two-sided and performed at a 0.05 significance level. The statistical analyses were performed using SAS $^{\circledR}$ statistical analysis software (v.9.4; SAS Institute, Cary, NC).

Sample size calculation was based on the study's primary aim, which refers to the proportion of patients achieving a meaningful improvement in their QoL according to the CAT, ie, attaining the MCID in the CAT total score. Considering the feasibility of this real-word study, a total of 300 patients were considered to be a representative sample of patients with COPD in Greece. Consequently, with a sample size of 300 patients and considering the maximum indetermination (ie, the worst-case proportion estimate of 0.5 ), a target population of 600,000 (ie, $10 \%$ of the adult population in Greece) and a binomial confidence level of $95 \%$, the percentage of patients achieving the minimum clinically important improvement in their CAT score can be determined with a confidence interval (CI) of $\pm 5.7 \%$. 


\section{Results}

\section{Patient Disposition}

A total of 286 patients were enrolled in the study from 15 hospital outpatient pulmonary clinics located in six different administrative regions in Greece; $58.0 \%$ of the total population was enrolled by nine clinics in the region of Attica. One non-eligible patient (aged $<40$ years) was excluded from the analysis, yielding a total of 285 eligible patients. The median [interquartile range (IQR)] duration of follow-up was 3.0 (3.0-3.1) months, with all patients attending the 12-week follow-up visit. Five patients discontinued therapy with aclidinium bromide due to adverse event occurred after a mean (standard deviation; SD) period of 2.8 (0.4) months; in four of these patients, the adverse events were assessed as causally related to aclidinium bromide (adverse drug reactions).

\section{Patients' Characteristics at Enrollment}

The patients' median age at enrollment was 69.0 years. The majority of patients were males $(76.3 \%)$, ever smokers (96.1\%; current smokers: 38.9\%), and overweight/ obese $(69.5 \%$; obese: $28.4 \%)$. The patients' sociodemographic and anthropometric characteristics at enrollment are presented in Table 1.

At least one comorbid condition was reported for $77.2 \%$ $(\mathrm{n}=220)$ of the patients, with $35.0 \%$ of those having one, $37.7 \%$ having two, and $27.3 \%$ having three or more comorbidities for a median (IQR) of 2.0 (1.0-2.0) comorbidities reported. Cardiovascular disorders were reported for $57.2 \%$ of the patients, metabolism/nutrition disorders for $30.9 \%$, and respiratory disorders (other than COPD) for 6.7\% (Table 1). Most common comorbidities, ie, those reported by $\geq 5 \%$, are presented in Table 1 .

\section{COPD Diagnosis and Treatment}

The median (IQR) COPD duration was $1.0(0.0-6.6)$ year, with $26.0 \%$ of the patients being newly-diagnosed (Table 1 ). Prior COPD therapy had been received by $73.3 \%$ of the patients. In particular, inhaled maintenance treatment (LABA and/or LAMA and/or ICS) for COPD management had been received by $71.9 \%$ of the patients, including ICS and LABA combinations in 54.0\% (as fixed-dose in 50.5\% and as free combination in 3.5\%); LAMA had been received by $34.4 \%$ of the patients (Table 2). Frequencies of prior drug classes are presented in Table 2.
Table I Patient and Disease Characteristics at Enrollment

\begin{tabular}{|c|c|}
\hline \multicolumn{2}{|l|}{ Patient Characteristics } \\
\hline $\operatorname{Sex}(N=279), n(\%)$ & \\
\hline Male & $213(76.3)$ \\
\hline Age $(N=285)$, [median $(\mathrm{IQR})]$, years & $69.0(62.0-75.0)$ \\
\hline Age Category ( $N=285), n(\%)$ & \\
\hline $40-55$ years & $30(10.5)$ \\
\hline $56-65$ years & $79(27.7)$ \\
\hline $66-75$ years & $105(36.8)$ \\
\hline$>75$ years & $71(24.9)$ \\
\hline BMI $(\mathrm{N}=285),[$ median $(\mathrm{IQR})], \mathrm{kg} / \mathrm{m}^{2}$ & $27.4(24.3-30.7)$ \\
\hline $\begin{array}{l}\text { BMI Category }(\mathrm{N}=285), \mathrm{n}(\%) \\
\text { Underweight }\left(\mathrm{BMI}<18.5 \mathrm{~kg} / \mathrm{m}^{2}\right) \\
\text { Normal }\left(I 8.5 \leq \mathrm{BMI}<25 \mathrm{~kg} / \mathrm{m}^{2}\right) \\
\text { Overweight }\left(25 \leq \mathrm{BMI}<30 \mathrm{~kg} / \mathrm{m}^{2}\right) \\
\text { Obese }\left(\mathrm{BMI} \geq 30 \mathrm{~kg} / \mathrm{m}^{2}\right)\end{array}$ & $\begin{array}{l}3(1 . I) \\
84(29.5) \\
117(4 I .1) \\
81(28.4)\end{array}$ \\
\hline $\begin{array}{l}\text { Smoking Status }(\mathrm{N}=285), \mathrm{n}(\%) \\
\text { Current smoker } \\
\text { Former smoker } \\
\text { Never smoker }\end{array}$ & $\begin{array}{l}\text { II I (38.9) } \\
\text { I } 63(57.2) \\
\text { II (3.9) }\end{array}$ \\
\hline $\begin{array}{l}\text { Time since smoking cessation }(\mathrm{N}=163) \text {, [median } \\
(\mathrm{IQR}) \text { ], years } \\
\text { Newly diagnosed with COPD }(\mathrm{N}=285), \mathrm{n}(\%) \\
\text { COPD duration }(\mathrm{N}=285) \text {, [median }(\mathrm{IQR}) \text { ], years } \\
\text { At least one comorbidity }(\mathrm{N}=285), \mathrm{n}(\%)\end{array}$ & $\begin{array}{l}7.0(2.5-16.0) \\
74(26.0) \\
1.0(0.0-6.0) \\
220(77.2)\end{array}$ \\
\hline $\begin{array}{l}\text { Comorbidity Categories }(\mathrm{N}=285), \mathrm{n}(\%) \\
\text { Cardiac/Vascular disorders } \\
\text { Metabolism/Nutrition disorders } \\
\text { Respiratory, thoracic, and mediastinal disorders } \\
\text { Other }\end{array}$ & $\begin{array}{l}163(57.2) \\
88(30.9) \\
19(6.7) \\
98(34.4)\end{array}$ \\
\hline $\begin{array}{l}\text { Comorbidities in } \geq 5 \% \text { of the Patients }(N=285) \text {, } \\
n(\%)\end{array}$ & \\
\hline Hypertension & $94(33.0)$ \\
\hline Diabetes mellitus & $54(18.9)$ \\
\hline Coronary artery disease & $51(17.9)$ \\
\hline Dyslipidemia & $35(12.3)$ \\
\hline Atrial fibrillation & $21(7.4)$ \\
\hline
\end{tabular}

Abbreviations: BMI, body mass index; COPD, chronic obstructive pulmonary disease; IQR, interquartile range.

Aclidinium bromide was initiated as add-on therapy in $74.3 \%$ of the patients with available data $(\mathrm{N}=253)$. Inhaled maintenance therapies (LABA and/or LAMA and/or ICS) were co-administered in $73.1 \%$, with most frequent coadministered medications being ICS and LABA combinations received by $62.5 \%$ [as fixed-dose combination in $60.5 \%$ and as free-drug regimens in $2.0 \%$ ]. Concomitant therapies per drug class are presented in Table 2 . 
Table 2 Prior and Concomitant Medications for COPD Management

\begin{tabular}{|c|c|}
\hline \multicolumn{2}{|c|}{ Prior and Concomitant Medications for COPD Managemen } \\
\hline Prior COPD treatment $(\mathrm{N}=285), \mathrm{n}(\%)$ & $209(73.3)$ \\
\hline Prior Treatment Classes $(\mathrm{N}=285), \mathrm{n}(\%)$ & \\
\hline Fixed ICS/LABA & $144(50.5)$ \\
\hline LAMA & $85(29.8)$ \\
\hline ICS & $29(10.2)$ \\
\hline LABA & $25(8.8)$ \\
\hline Fixed LAMA/LABA & $13(4.6)$ \\
\hline Fixed SAMA/SABA & $12(4.2)$ \\
\hline SABA & $9(3.2)$ \\
\hline SAMA & $8(2.8)$ \\
\hline LTRA & $4(1.4)$ \\
\hline PDE4 inhibitor & $4(1.4)$ \\
\hline Xanthines & $4(1.4)$ \\
\hline Other $^{a}$ & $5(1.8)$ \\
\hline Not specified & $\mathrm{I}(0.4)$ \\
\hline $\begin{array}{l}\text { Aclidinium bromide initiation as add-on therapy } \\
\left(\mathrm{N}=253^{\mathrm{b}}\right), \mathrm{n}(\%)\end{array}$ & $188(74.3)$ \\
\hline Concomitant Treatment Classes $\left(\mathrm{N}=253^{\mathrm{b}}\right), \mathrm{n}(\%)$ & \\
\hline Fixed ICS/LABA & $153(60.5)$ \\
\hline LABA & $20(7.9)$ \\
\hline ICS & $14(5.5)$ \\
\hline PDE4 inhibitor & $7(2.8)$ \\
\hline SABA & $5(2.0)$ \\
\hline LTRA & $3(1.2)$ \\
\hline LAMA & $\mathrm{I}(0.4)$ \\
\hline Other ${ }^{c}$ & $3(1.2)$ \\
\hline Not specified & $3(1.2)$ \\
\hline
\end{tabular}

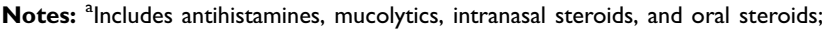
${ }^{b}$ Patients with available data; ${ }^{C}$ Includes mucolytics and intranasal steroids. Abbreviations: COPD, chronic obstructive pulmonary disease; ICS, inhaled corticosteroids; LABA, long-acting $\beta$ agonists; LAMA, long-acting muscarinic antagonists; LTRA, leukotriene receptor antagonist; SABA, short-acting $\beta$ agonists; SAMA, short-acting muscarinic antagonists; PDE4, phosphodiesterase 4.

\section{Effects of Aclidinium Bromide Therapy on Disease-Related QoL (CAT)}

The patients' median (IQR) total CAT score at enrollment was $14.0(9.0-20.0)$ points [mean (SD), 14.7 (7.8)], with $70.5 \%$ of the patients having a score $\geq 10$ points (Figure 1 ). At the 12-week follow-up visit, the median (IQR) total CAT score was $10.0 \quad(6.0-15.0)$, demonstrating a statistically significant median (IQR) decrease of 3.0 $(2.0-5.0)$ points $(\mathrm{p}<0.001)$. In addition, $76.5 \%$ of the patients achieved the MCID (minimum clinically important reduction of $\geq 2$ points) in their CAT score. Statistically significant reductions were observed in the scores of all CAT items between enrollment and the 12-week follow-up $(\mathrm{p}<0.001$ for all).
Effects of Aclidinium Bromide Therapy on Night-Time and Early-Morning COPD Symptoms

The frequency of reported night-time COPD symptoms was reduced from $63.2 \%$ of patients at enrollment to $50.5 \%$ at the 12 -week follow-up visit. The severity of these symptoms, as assessed by the physicians, statistically significantly decreased from enrollment at the follow-up visit [from a median (IQR) of $1.0(0.0-2.0)$ at enrollment to $0.0(0.0-1.0)$ at the follow-up visit; $p<0.001]$.

In addition, in patients with paired data, the prevalence of night-time symptoms of at least moderate severity decreased from $28.2 \%(78 / 277)$ at enrollment to $19.1 \%(53 / 277)$ at the follow-up visit $(\mathrm{p}<0.001)$. In particular, among patients with night-time symptoms of at least moderate severity $(\mathrm{N}=78)$, $41.0 \%$ (32/78) transitioned to no or mild night-time symptoms, while among those with no or mild night-time symptoms at enrolment $(\mathrm{N}=199), 3.5 \%(7 / 199)$ transitioned to night-time symptoms of at least moderate severity. Distribution of patients with available data according to the severity of their night-time symptoms is displayed in Figure 2A. Furthermore, in patients with paired data, the proportion of patients with nocturnal awakenings due to COPD decreased from $46.8 \%$ (118/252) at enrollment to $32.9 \%(83 / 252)$ at the follow-up visit $(\mathrm{p}<0.001)$.

Moreover, $97.2 \%$ of the patients had early-morning symptoms at enrollment and $96.5 \%$ at the follow-up visit. The severity of these symptoms, as assessed by the physicians, significantly decreased from enrollment at the follow-up visit [from a median (IQR) of $2.0(1.0-2.0)$ at enrollment to $1.0(1.0-2.0)$ at the follow-up visit; $\mathrm{p}<0.001]$. In patients with paired data, the percentage of patients with symptoms of at least moderate severity declined from $63.6 \%(173 / 272)$ at enrollment to $34.2 \%$ $(93 / 272)$ at the follow-up visit $(p<0.001)$. In particular, among patients with early-morning symptoms of at least moderate severity ( $\mathrm{N}=173), 49.7 \%$ (86/173) transitioned to no or mild early-morning symptoms, while among those with no or mild early-morning symptoms at enrolment $(\mathrm{N}=99), 6.1 \%$ (6/99) transitioned to symptoms of at least moderate severity. Distribution of patients with available data according to the severity of their early morning symptoms are displayed in Figure 2A.

Early-morning symptoms reported as being the most troublesome by the patients at enrollment were difficulty in breathing [reported by $75.9 \%$ (214/282)], cough [by $68.0 \%$ (193/284)], wheezing/breath sounds [by 66.8\% 


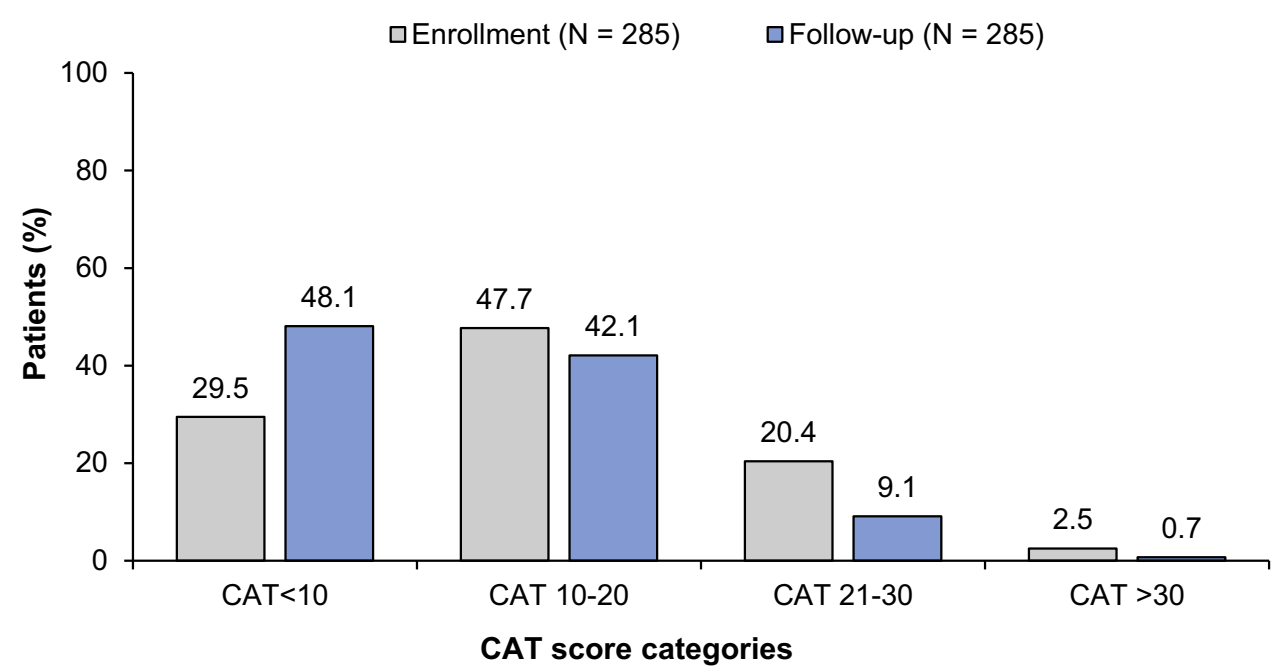

Figure I Chronic obstructive pulmonary disease assessment test (CAT) scores at enrollment and at the I2-week follow-up visit. Patient distribution in different categories according to their CAT scores at enrollment (dark grey bars) and at the follow-up visit (light grey bars) is displayed. The numbers above bars indicate the percentage of patients in each CAT score category, as indicated in the $\mathrm{x}$-axis.

$(189 / 283)]$, and difficulty in clearing mucus [by $58.1 \%$ $(165 / 284)]$. The severity of difficulty in breathing, wheezing/breath sounds, difficulty in clearing mucus, and cough was rated by the patients as being at least moderate in $53.9 \%$ (152/282), 42.0\% (119/283), 38.5\% (109/283), and $42.0 \%(119 / 283)$ of evaluable patients at enrollment, respectively, and in 31.1\% (88/283), 16.1\% (46/285), $19.6 \%(56 / 285)$, and $20.9 \%(59 / 282)$ of evaluable patients at the follow-up visit, respectively (Figure $2 \mathrm{~B}$ ).

\section{Impact of COPD Symptoms on the Patients' Daily Activities}

At enrollment, 59.5\% (169/284) of patients with paired enrollment and follow-up data reported being at least moderately impaired in the performance of their daily activities due to their COPD symptoms, with this percentage decreasing to $38.7 \%(110 / 284)$ at the 12 -week follow-up visit $(\mathrm{p}<0.001)$. Distribution of patients with available data according to the level of impairment of their daily activities at enrollment and at the follow-up visit is displayed in Figure 3.

\section{Evaluation of Aclidinium Bromide Inhaler Device and Willingness to Continue}

\section{Therapy}

Therapy with aclidinium bromide inhaler was rated by physicians and patients as the preferred COPD treatment for $97.1 \%(233 / 240)$ and $93.4 \%(225 / 241)$ of patients with available data, respectively. Moreover, the features of the inhaler were rated as being very good or good in more than $90 \%$ of patients with available data by both physicians and patients (Table 3).

Physicians declared their intention to continue therapy with aclidinium bromide after the end of the study for $92.6 \%(262 / 283)$ of their patients, with good effectiveness of the treatment $(90.5 \%)$ and good handling of the inhaler device $(69.4 \%)$ reported as the main reasons for therapy continuation. Similarly, 92.3\% (263/285) of the patients intended to continue therapy after the end of the study, citing good effectiveness $(86.8 \%)$ and good handling $(64.2 \%)$ as the main reasons.

\section{Predictors of Improvement in the Total CAT Score and of Achievement of an MCID at 12 Weeks Post-Enrollment}

Univariable (Supplementary Figure 1) and multivariable (Figure 4) logistic regression analyses were performed to examine the association of various factors of interest with the achievement of the total CAT MCID at 12 weeks postenrollment. The best-fitted multivariable model included the following factors: obesity $\left(\mathrm{BMI} \geq 30 \mathrm{~kg} / \mathrm{m}^{2}\right)$, smoking status, newly-diagnosed COPD, CAT score at enrollment, no prior treatment with LAMA, and at least moderate early-morning and/or night-time symptoms. In particular, the odds of achieving the MCID were about three times higher [adjusted odds ratio $\left(\mathrm{OR}_{\text {adjusted }}\right): 2.75,95 \% \mathrm{CI}$ : 1.17-6.44; $\mathrm{p}=0.020$ ] for newly-diagnosed versus previously diagnosed patients with COPD, and more than 
A

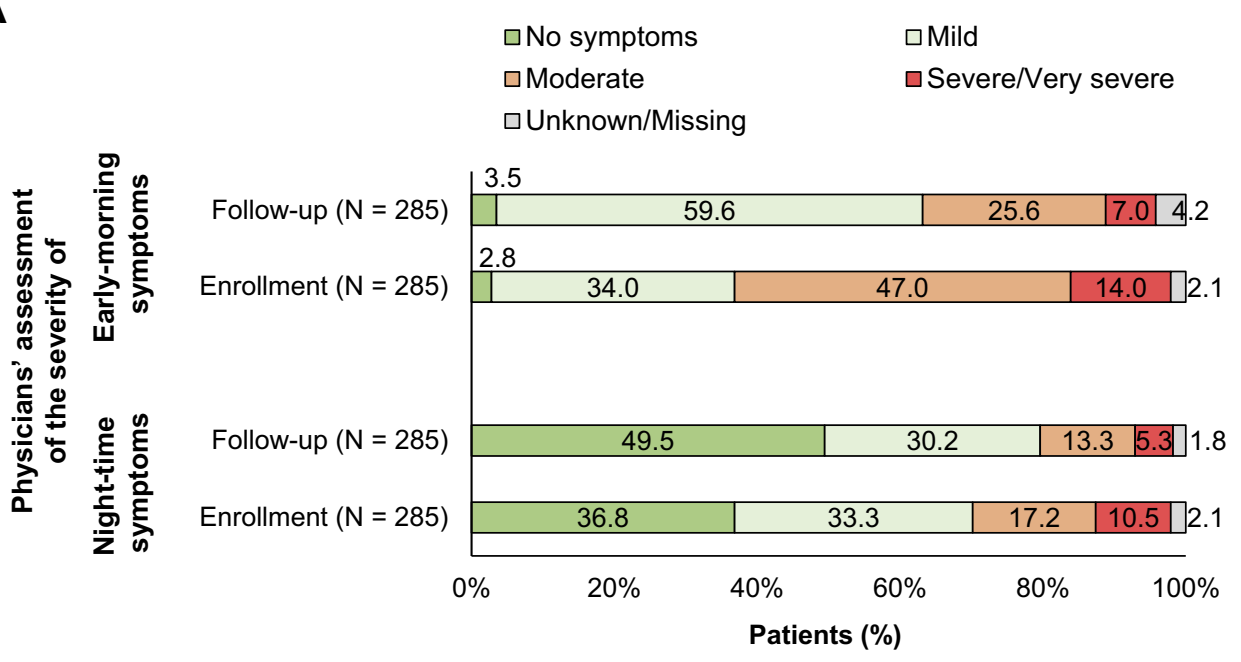

B

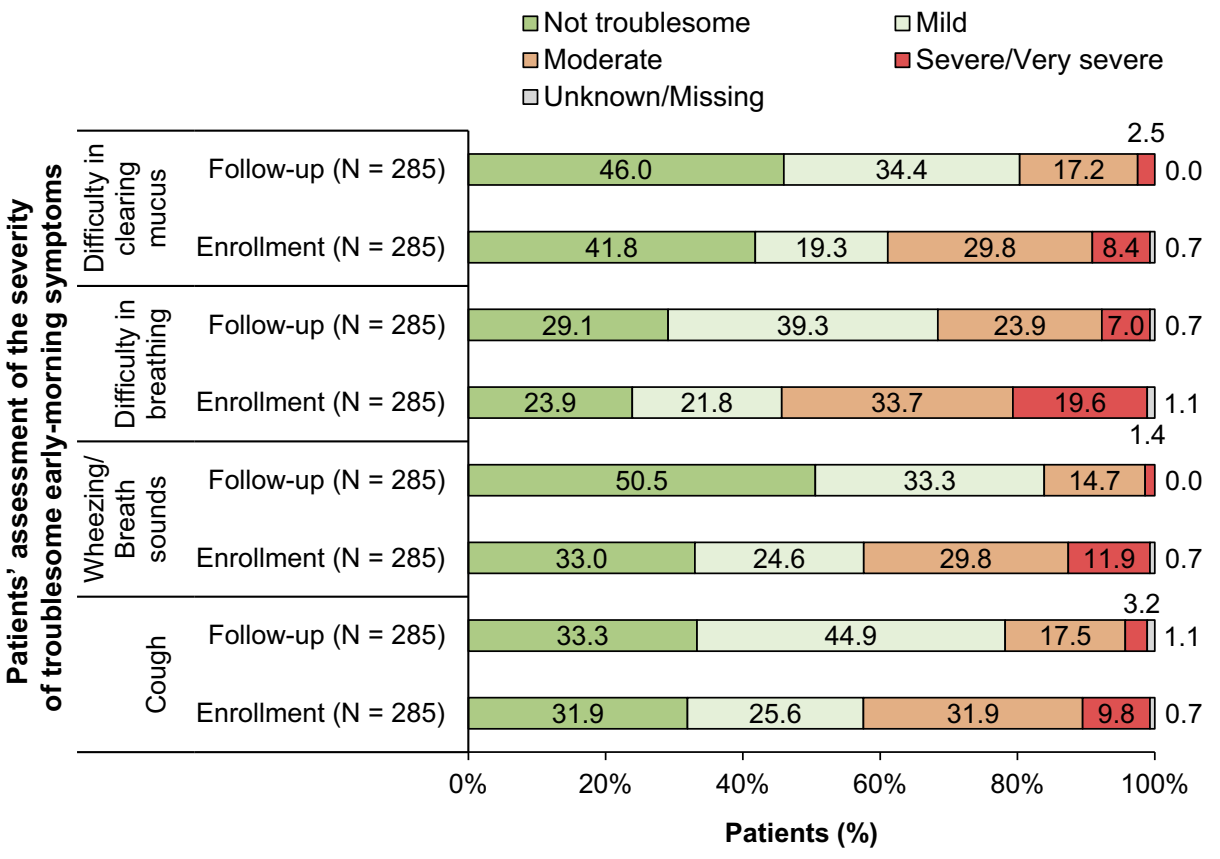

Figure 2 Severity of early-morning and night-time symptoms at enrollment and at the I2-week follow-up visit. (A) Patient distribution according to the physician-assessed severity of early-morning and night-time symptoms at enrollment and at the follow-up visit. Numbers indicate the percentages of patients. (B) Patient distribution according to the severity of troublesome early-morning symptoms as perceived by the patients at enrollment and at the follow-up visit. Numbers indicate the percentages of patients.

two times higher ( $\mathrm{OR}_{\text {adjusted: }}$ 2.27, 95\% CI: $1.13-4.57 ; \mathrm{p}=$ 0.021 ) for patients with than without at least moderate early-morning and/or night-time symptoms. Moreover, for each point of higher total CAT score at enrollment, the odds of attaining the MCID increased by $10 \%$ $\left(\mathrm{OR}_{\text {adjusted }}\right.$ : $\left.1.10,95 \% \mathrm{CI}: 1.04-1.16 ; \mathrm{p}<0.001\right)$, when adjusting for the other factors remaining in the model (Figure 4).

In addition, the following factors were found to be statistically significantly associated with a greater decrease in the total CAT score from enrollment at the 12-week post- enrollment visit through univariable linear regression models: male sex, age at enrollment $\geq 65$, newly-diagnosed with COPD, initiation of aclidinium bromide as add-on therapy with other inhaled maintenance treatment, presence of night-time symptoms, and at least moderate early-morning and/or night-time symptoms (Supplementary Table 1).

\section{Safety}

A total of seven adverse events were reported for five patients $(1.8 \%)$, of which six [experienced by four (1.4\%) patients] were assessed to be causally related to 
口Enrollment $(\mathrm{N}=285) \quad$ 口Follow-up $(\mathrm{N}=285)$

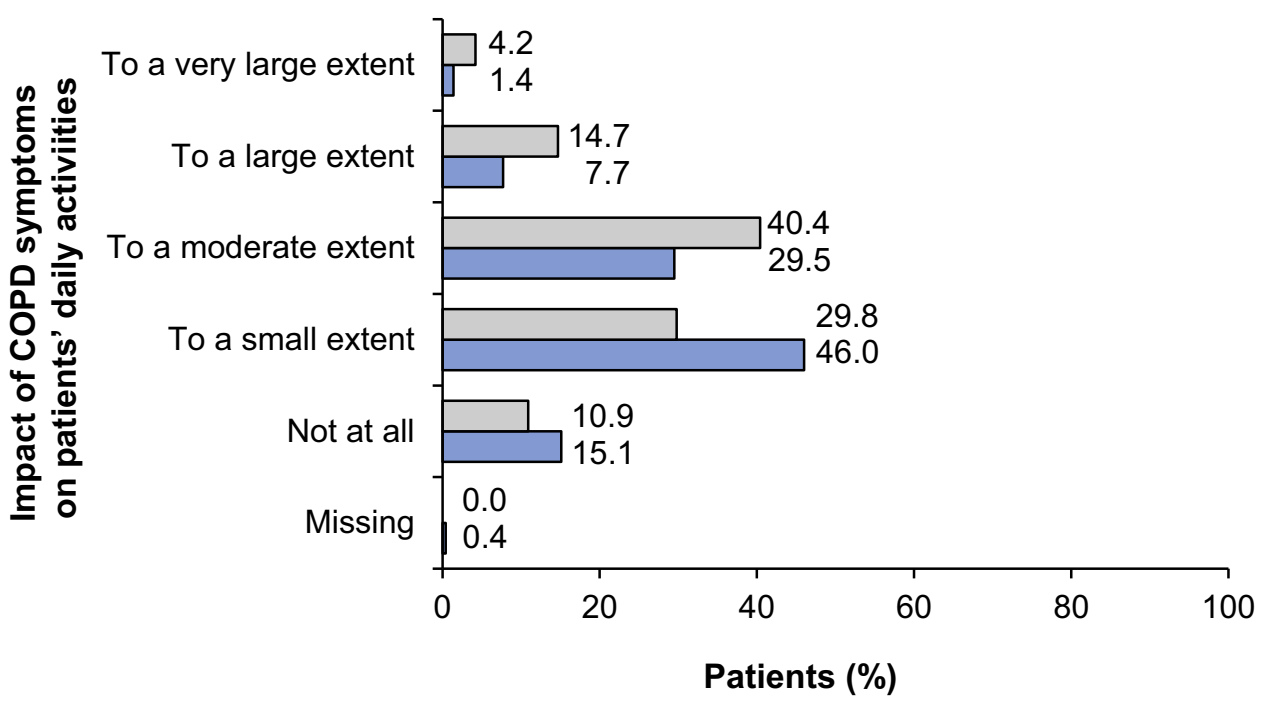

Figure 3 Patient distribution according to the impact of chronic obstructive pulmonary disease symptoms on the patients' daily activities at enrollment (dark grey bars) and at the 12-week follow-up visit (light grey bars).

aclidinium bromide. The events related to aclidinium bromide were all non-serious and included two cases of drug ineffectiveness, two cases of cough/productive cough, one case of dyspnea, and one of paroxysmal tachycardia. Of these, dyspnea and productive cough were experienced by a patient for whom "drug ineffectiveness" was also reported and referred to lack of improvement of these two symptoms. One serious event of pleural effusion, which was not assessed to be causally related to aclidinium bromide, was experienced by one patient. All events led to study treatment discontinuation.

\section{Discussion}

The current study provides real-world data demonstrating the favorable benefit-risk profile of aclidinium bromide, when used in the routine care setting of Greece, with special focus on disease-related QoL and night-time and early-morning symptom burden.

The patients' mean CAT total score significantly decreased by a mean of 3.7 points after 12 weeks of aclidinium treatment, a decrease greater than the MCID. ${ }^{24}$ In agreement to the current findings, two studies in Austria by Olschewski et al (Austrian ON-AIR) ${ }^{19}$ and Marth et al, ${ }^{20}$ of a similar design, found significant reductions in CAT scores by a mean of 5.5 and 4.7 points, respectively, after 12 weeks of aclidinium treatment. The larger reduction observed in the studies by Olschewski et $\mathrm{al}^{19}$ and Marth et $\mathrm{al}^{20}$ might be justified by the fact that they enrolled patients with a higher mean baseline CAT score (18.4 and 18.5 points, respectively, versus 14.7 in the present study) indicating the presence of more severe symptoms at baseline; in addition, these two studies included greater proportions of patients with nighttime symptoms of at least moderate severity $(56.1 \%$ and $45.0 \%$, respectively, versus $28.3 \%$ in the present study) and with newly-diagnosed COPD $(31.2 \%$ and $33.8 \%$, respectively, versus $26.0 \%$ ). All above three factors were identified as significant predictors of achieving a decrease in the total CAT score according to linear regression models. Baseline CAT score and new diagnosis of COPD were also among the strongest predictors of achieving an MCID in the total CAT score according to multivariable logistic regression analysis. Correspondingly, the MCID attainment rate was $71.9 \%$ in the present study compared to $85.2 \%$ in the study by Olschewski et $\mathrm{al}^{19}$ and $75.2 \%$ in the study by Marth et al. ${ }^{20}$ The association of the baseline CAT score with the reduction in the total CAT score after 12 weeks of aclidinium treatment has been reported elsewhere. ${ }^{21}$ Furthermore, a greater reduction in the total CAT score among newly-diagnosed patients with COPD was also observed in the study of Marth et al. ${ }^{20}$ The beneficial effect of aclidinium bromide on attainment of the MCID in the present study was not found to be impacted by the patients' smoking status and, presence of obesity, in agreement with a previous report. ${ }^{21}$ Also in alignment with a previous report, ${ }^{21}$ prior use of another LAMA was shown to be advantageous in terms of CAT score decrease; however, this factor was not shown to be associated with achievement of the MCID when adjusted for other factors. It should also be mentioned that about $75 \%$ of the patients initiated 
Table 3 Evaluation of the Features of the Aclidinium Bromide Inhaler According to the Physicians and the Patients

\begin{tabular}{|c|c|c|}
\hline & $\begin{array}{l}\text { Patients, } \\
\text { n (\%) }\end{array}$ & $\begin{array}{l}\text { Physicians, } \\
\text { n (\%) }\end{array}$ \\
\hline \multicolumn{3}{|l|}{ Ease of Use } \\
\hline Very good/Good & $262(91.9)$ & $273(95.8)$ \\
\hline Neutral & $16(5.6)$ & $10(3.5)$ \\
\hline Bad & $5(1.8)$ & $\mathrm{I}(0.4)$ \\
\hline Unknown/Missing & $2(0.7)$ & I (0.4) \\
\hline \multicolumn{3}{|l|}{ Comfort } \\
\hline Very good/Good & $259(90.9)$ & $275(96.5)$ \\
\hline Neutral & $19(6.7)$ & $8(2.8)$ \\
\hline Bad & $3(1.1)$ & $\mathrm{I}(0.4)$ \\
\hline Unknown/Missing & $4(1.4)$ & $\mathrm{I}(0.4)$ \\
\hline \multicolumn{3}{|l|}{ Ease of Understanding Device Handling } \\
\hline Very good/Good & $263(92.3)$ & $270(94.7)$ \\
\hline Neutral & $15(5.3)$ & $12(4.2)$ \\
\hline Bad & $6(2.1)$ & $\mathrm{I}(0.4)$ \\
\hline Unknown/Missing & $\mathrm{I}(0.4)$ & $2(0.7)$ \\
\hline \multicolumn{3}{|l|}{ Holding } \\
\hline Very good/Good & $256(89.8)$ & $273(95.8)$ \\
\hline Neutral & $27(9.5)$ & $10(3.5)$ \\
\hline Bad & $\mathrm{I}(0.4)$ & $\mathrm{I}(0.4)$ \\
\hline Unknown/Missing & I $(0.4)$ & I (0.4) \\
\hline \multicolumn{3}{|l|}{ Ability to Handle } \\
\hline Very good/Good & $262(91.9)$ & $27 \mid(95.1)$ \\
\hline Neutral & $17(6.0)$ & $12(4.2)$ \\
\hline Bad & $5(1.8)$ & $\mathrm{I}(0.4)$ \\
\hline Unknown/Missing & $\mathrm{I}(0.4)$ & $\mathrm{I}(0.4)$ \\
\hline \multicolumn{3}{|l|}{ Ease of Dose Preparation } \\
\hline Very good/Good & $264(92.6)$ & $273(95.8)$ \\
\hline Neutral & $16(5.6)$ & $10(3.5)$ \\
\hline Bad & $3(1.1)$ & $\mathrm{I}(0.4)$ \\
\hline Unknown/Missing & $2(0.7)$ & I (0.4) \\
\hline \multicolumn{3}{|l|}{ Control Mechanism for Correct Inhalation } \\
\hline Very good/Good & $262(91.9)$ & $272(95.4)$ \\
\hline Neutral & $19(6.7)$ & II (3.9) \\
\hline Bad & $3(1.1)$ & $\mathrm{I}(0.4)$ \\
\hline Unknown/Missing & $\mathrm{I}(0.4)$ & I (0.4) \\
\hline
\end{tabular}

aclidinium bromide as add-on therapy (including more than $70 \%$ who received other concomitant maintenance therapies, mainly ICS and LABA combinations), which could be considered as a confounder of the study outcomes; nonetheless, this factor was not found to be associated with MCID attainment.

In the present study, aclidinium bromide also led to significant improvements in the severity of both early-morning and night-time symptoms after 12 weeks of treatment. In particular, the percentage of patients with at least moderate night-time symptoms declined from $28.3 \%$ to $18.9 \%$, while those with at least moderate early-morning symptoms dropped from $62.4 \%$ to $34.1 \%$. Reductions in symptom severity were noted for all individual symptoms examined. Similar findings have been reported in other real-world studies after 12 weeks of aclidinium bromide treatment, ${ }^{19-21}$ complementing the data from earlier Phase III studies. ${ }^{18,26}$ As we expected, improvements in symptom severity were accompanied by a decrease in the number of nocturnal awakenings.

The circadian variability of COPD symptoms, which may be explained by the circadian modulation of the airway caliber by the cholinergic system, is amply documented. ${ }^{10,27,28}$ Accordingly, through their ability to modulate the cholinergic tone, LAMAs constitute especially good therapeutic options for controlling COPD symptoms, with the twice-daily dosing of aclidinium bromide boosting the bronchodilation effect on airways and thus improving the night-time and early-morning symptoms. ${ }^{10}$ Moreover, aclidinium-induced improvements in cough and sputum symptoms are supported by its antitussive activity, which is mediated by acid-sensing ion channels and mechanoreceptors. ${ }^{26}$ These characteristics of aclidinium may explain why in a phase IIIb study, aclidinium, but not tiotropium, compared to placebo yielded significant reductions in the severity of night-time and individual early-morning (cough, wheeze, shortness of breath, and phlegm) symptoms, as well as an improvement in activity limitation due to COPD symptoms. ${ }^{18}$ Improvement in symptom severity should be a priority for patients with COPD, as symptoms have been associated with disease exacerbations, as well as with daily activity impairment, physical activity and sleep impairments, anxiety, and depression. ${ }^{7,8,27,29-32}$ Even though the association of symptoms with daily activities in the present study was not directly examined, significant improvement of the patient-perceived impact of symptoms on their daily activities was observed, in agreement with the study by Marth et al. ${ }^{20}$

In addition, in this study, more than $90 \%$ of patients and physicians considered aclidinium inhaler as the preferred treatment, and more than $90 \%$ rated all features of the inhaler as being "good" or "very good". Similarly, high patient satisfaction with the device's usability and high overall patient satisfaction have been previously reported. ${ }^{11,12}$ Patients' satisfaction with the treatment translated into an intention to continue with aclidinium after the end of the study by more than $90 \%$ of the patients. High ratings of the device features were also reported in the study by Marth et al, ${ }^{20}$ wherein about 


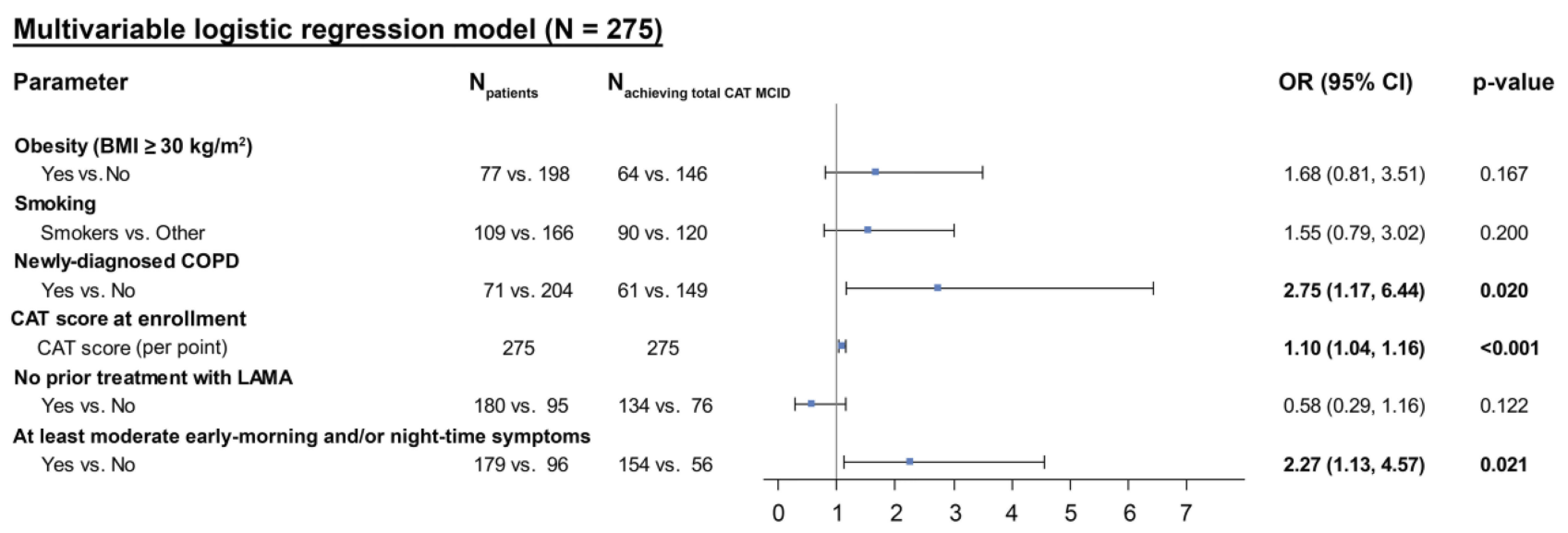

Figure 4 Multivariable regression analyses of the association of patient and disease characteristics with achievement of the minimum clinically important difference (MCID) in the total chronic obstructive pulmonary disease (COPD) assessment test (CAT) score from enrollment to the I2-week follow-up visit. The final multivariable logistic model (based on minimization of Akaike information criterion) included the following factors: obesity [body mass index (BMl) $\geq 30 \mathrm{~kg} / \mathrm{m}^{2}$ ], smoking status, newly-diagnosed COPD, CAT score at enrollment, no prior treatment with long-acting muscarinic antagonists (LAMA), at least moderate early-morning and/or night-time symptoms. Bold values indicate statistical significance. Abbreviations: $\mathrm{Cl}$, confidence interval; ICS, inhaled corticosteroids; LABA, long-acting $\beta$ agonists; OR, odds ratio.

$80 \%$ of patients and physicians reported they intended to continue therapy after the study.

Regarding aclidinium's safety profile, the incidence of adverse events over the 12-week observation period was very low, with only six adverse drug reactions reported, none of which was serious. A low incidence of adverse events has been reported in other real-world studies, ${ }^{19-21}$ likely attributed to the fast hydrolysis of aclidinium in the plasma, a pharmacokinetic feature that distinguishes it from other LAMAs. $^{33}$

Limitations of the study include the lack of control group and the absence of data on the patients' baseline airflow limitation severity and exacerbation risk. Moreover, lung function indices were not recorded during study participation. Furthermore, as all patients were enrolled by pulmonology specialists practicing in hospital outpatient clinics, the study results are generalizable to outpatients managed by hospital-based physicians rather to patients cared for in diverse ambulatory care settings also including private practices. However, enrollment of the patients by 15 public and private hospital clinics from geographically diverse locations of Greece where $74 \%$ of the Greek population resides, accounts for variations in medical practice and strengthens the generalizability of the outcomes in hospital outpatient settings. Notably, the study had a very low attrition rate, thus preventing bias arising from selectively missing data from patients who would prematurely discontinue study participation due to study treatment discontinuation as a result of inadequate response.

\section{Conclusion}

In agreement with results from randomized controlled trials, this observational real-world study has demonstrated that 12 weeks of treatment with aclidinium bromide produces a significant and clinically meaningful improvement in the quality of life of COPD patients, while reducing night-time and early-morning symptom burden and activity impairment, which is accompanied by a favorable safety profile and a high level of patient satisfaction with treatment.

\section{Abbreviations}

BMI, body mass index; CAT, COPD Assessment Test; CI, confidence intervals; COPD, chronic obstructive pulmonary disease; E-RS:COPD, evaluating respiratory symptoms in COPD; GOLD, Global Initiative for Chronic Obstructive Lung Disease; ICS, inhaled corticosteroid; IQR, interquartile range; LABA, long-acting $\beta$ agonists; LAMA, long-acting muscarinic antagonists; MCID, minimum clinically important difference; QoL, quality of life; SmPC, summary of product characteristics; SD, standard deviation.

\section{Data Sharing Statement}

The datasets generated and analyzed during the current study are not publicly available as they contain information that could compromise the privacy of the participants but are available from GD upon reasonable request.

\section{Acknowledgments}

The authors would like to thank the following Investigators (listed in alphabetical order) for their 
participation in the study: Daniil Daniilidis, General Hospital of Kavala, Kavala, Greece; Aikaterini Dimakou, 5th Respiratory Medicine Department, Athens Chest Hospital "Sotiria", Athens, Greece; Mina Gaga, 7th Respiratory Medicine Department, Athens Chest Hospital "Sotiria", Athens, Greece; Konstantinos Gourgouliannis, Department Internal Medicine, University Hospital of Larissa, Larissa, Greece; Nikolaos G. Koulouris, 1st Academic Department of Pneumonology, Athens Chest Hospital "Sotiria", Athens, Greece; Stavros Tragaras, Thriasio General Hospital of Elefsina, Attica, Greece; Michalis Toumbis, 6th Respiratory Medicine Department, Athens Chest Hospital "Sotiria", Athens, Greece; Konstantinos Zarogoulidis, Pulmonary Department, "G. Papanikolaou" General Hospital of Thessaloniki, Thessaloniki, Greece.

The authors would like to thank Qualitis Ltd. for editorial support, which was supported by funding from Menarini Hellas.

List of the 15 hospital clinics participating in the study: Department of Pulmonary Medicine, Metropolitan Hospital, Athens, Greece; 1st Academic Department of Pneumonology, Athens Chest Hospital "Sotiria", Athens, Greece; Democritus University of Thrace/University General Hospital, Alexandroupolis, Greece; Department of Respiratory Medicine, "Evangelismos" General Hospital, Athens, Greece; Department of Occupational Lung Disease and Tuberculosis "Sismanogleio-Amalia Fleming" General Hospital, Athens, Greece; General Hospital of Kavala, Kavala, Greece; 2nd Pulmonary Medicine Department, General University Hospital "Attikon", Athens, Greece; Pulmonary Department, "G. Papanikolaou" General Hospital of Thessaloniki, Thessaloniki, Greece; 5th Respiratory Medicine Department, Athens Chest Hospital "Sotiria", Athens, Greece; 6th Respiratory Medicine Department, Athens Chest Hospital "Sotiria", Athens, Greece; 7th Respiratory Medicine Department, Athens Chest Hospital "Sotiria", Athens, Greece; Respiratory Medicine Department, Thriasio General Hospital of Elefsina, Attica, Greece; Respiratory Medicine Department, University Hospital of Ioannina, Ioannina, Greece; University Hospital of Heraklion, Medical School, University of Crete, Crete, Greece; University Hospital of Larissa, Larissa, Greece.

Trademark acknowledgment: Genuair ${ }^{\circledR}$ is a trademark of AstraZeneca $A B$, and Bretaris ${ }^{\circledR}$ is a trademark of Almirall, S.A.

\section{Author Contributions}

All authors contributed to data acquisition and/or interpretation, drafting and revising the article, gave final approval of the version to be published, and agree to be accountable for all aspects of the work.

\section{Funding}

The study was sponsored by Menarini Hellas. The study Sponsor was involved in the study concept and design and in the interpretation of the data included in this publication, but not in the data collection and analysis. Menarini Hellas also funded the medical writing support for this publication.

\section{Disclosure}

KK was an employee of Novartis Pharma AG at the time of the study; he has received consulting/lecture fees from AstraZeneca, Boehringer Ingelheim, Chiesi, ELPEN, GSK, Menarini, and Novartis. AK, EK, EM, SP received honoraria from Menarini Hellas during the conduct of the study and reports grants and personal fees from AstraZeneca, Boehringer Ingelheim, Chiesi, ELPEN, Novartis, and GSK, grants from Innovis and Menarini, and personal fees from Sanofi outside the submitted work. PS reports personal fees from AstraZeneca, Boehringer Ingelheim, ELPEN, GSK, Menarini Hellas, Novartis, Roche, and grants and personal fees from Chiesi. TV and NT have no conflicts of interest to disclose. GD is an employee of Menarini Hellas and works as a medical director at MENARINI. The authors report no other conflicts of interest in this work.

\section{References}

1. Lopez AD, Shibuya K, Rao C, et al. Chronic obstructive pulmonary disease: current burden and future projections. Eur Respir J. 2006;27:397-412.

2. Buist AS, McBurnie MA, Vollmer WM, et al.; BOLD Collaborative Research Group. International variation in the prevalence of COPD (the BOLD Study): a population-based prevalence study. Lancet. 2007;370:741-750. doi:10.1016/S0140-6736(07)61377-4

3. Mathers CD, Loncar D. Projections of global mortality and burden of disease from 2002 to 2030. PLoS Med. 2006;3(11):e442. doi:10.1371/ journal.pmed.0030442

4. Institute for Health Metrics and Evaluation. Country Profiles. Greece. Available from: http://www.healthdata.org/greece. Accessed June 21, 2019.

5 Contoli M, Solidoro P, Di Marco F, et al. Effects of aclidinium on determinants of COPD severity: symptoms and quality of life. Int J Chron Obstruct Pulmon Dis. 2016;11:3043-3050. doi:10.2147/COPD

6. Kessler R, Partridge MR, Miravitlles M, et al. Symptom variability in patients with severe COPD: a pan-European cross-sectional study. Eur Respir J. 2011;37:264-272. doi:10.1183/09031936.00051110

7. Miravitlles M, Worth H, Soler Cataluña JJ, et al. Observational study to characterise 24-hour COPD symptoms and their relationship with patient-reported outcomes: results from the ASSESS study. Respir Res. 2014;15:122. doi:10.1186/s12931-014-0122-1 
8. Ding B, Small M, Bergström G, Holmgren U. A cross-sectional survey of night-time symptoms and impact of sleep disturbance on symptoms and health status in patients with COPD. Int J Chron Obstruct Pulmon Dis. 2017;12:589-599. doi:10.2147/COPD

9. Global Strategy for the Diagnosis, Management and Prevention of Chronic Obstructive Pulmonary Disease, Global Initiative for Chronic Obstructive Lung Disease (GOLD); 2019. Available from: http://www.goldcopd.org. Accessed June 21, 2019.

10. Blasi F, Canonica GW, Miravitlles M. Is aclidinium alone or combined with a LABA a rational choice for symptomatic COPD patients? Respir Res. 2017;18:19. doi:10.1186/s12931-017-0506-0

11. Blasi F, Canonica GW, Centanni S, et al. Genuair ${ }^{\circledR}$ usability test: results of a national public survey of the elderly. COPD. 2016;13:367-371. doi:10.3109/15412555.2015.1067675

12. Magnussen H, Fyrnys B, Greguletz R. Genuair ${ }^{\circledR} /$ Pressair $^{\circledR}$ Inhaler in COPD: The Patient Perspective. COPD. 2019;16:196-205.

13. Wedzicha JA, Agusti A, Donaldson G, Chuecos F, Lamarca R, Garcia Gil E. Effect of aclidinium bromide on exacerbations in patients with moderate-to-severe COPD: a pooled analysis of five Phase III, randomized, placebo-controlled studies. COPD. 2016;13:669-676. doi:10.3109/15412555.2016.1170111

14. D’Urzo AD, Rennard SI, Kerwin EM, Mergel V, Leselbaum AR, Caracta CF. AUGMENT COPD study investigators. Efficacy and safety of fixed-dose combinations of aclidinium bromide/formoterol fumarate: the 24-week, randomized, placebo-controlled AUGMENT COPD study. Respir Res. 2014;15:123. doi:10.1186/s12931-014-0123-0

15. Jones PW, Singh D, Bateman ED, et al. Efficacy and safety of twice-daily aclidinium bromide in COPD patients: the ATTAIN study. Eur Respir J. 2012;40:830-836. doi:10.1183/09031936.00225511

16. Kerwin EM, D’urzo AD, Gelb AF, Lakkis H, Garcia Gil E, Caracta CF. ACCORD I study investigators. Efficacy and safety of a 12-week treatment with twice-daily aclidinium bromide in COPD patients (ACCORD COPD I). COPD. 2012;9:90-101. doi:10.3109/ 15412555.2012.661492

17. Rennard SI, Scanlon PD, Ferguson GT, et al. ACCORD COPD II: a randomized clinical trial to evaluate the 12-week efficacy and safety of twice-daily aclidinium bromide in chronic obstructive pulmonary disease patients. Clin Drug Investig. 2013;33:893-904. doi:10.1007/ s40261-013-0138-1

18. Beier J, Kirsten AM, Mróz R, et al. Efficacy and safety of aclidinium bromide compared with placebo and tiotropium in patients with moderate-to-severe chronic obstructive pulmonary disease: results from a 6-week, randomized, controlled Phase IIIb study. COPD. 2013;10:511-522. doi:10.3109/15412555.2013.814626

19. Olschewski H, Voves R, Wallner E, Scheidl S, Kovacs G, Trinker M. Wirksamkeit, Sicherheit und Benutzerfreundlichkeit der Trockenpulver-Inhalation von Aclidiniumbromid bei COPD. Atemwegs Lungenkr. 2018;44(1):39-50. doi:10.5414/ATX02273

20. Marth K, Schuller E, Pohl W. Improvements in patient-reported outcomes: a prospective, non-interventional study with aclidinium bromide for treatment of COPD. Respir Med. 2015;109:616-624. doi:10.1016/j.rmed.2015.02.004
21. Lange P, Godtfredsen NS, Olejnicka B, et al. Symptoms and quality of life in patients with chronic obstructive pulmonary disease treated with aclidinium in a real-life setting. Eur Clin Respir J. 2016;3:31232. doi:10.3402/ecrj.v3.31232

22. Public Policy Committee, International Society of Pharmacoepidemiology. Guidelines for good pharmacoepidemiology practice (GPP). Pharmacoepidemiol Drug Saf. 2016;25:2-10. doi: $10.1002 /$ pds.3891

23. Likert R. A technique for the measurement of attitudes. Arch Psychol. 1932;22:55.

24. Kon SSC, Canavan JL, Jones SE, et al. Minimum clinically important difference for the COPD assessment test: a prospective analysis. Lancet Respir Med. 2014;2:195-203. doi:10.1016/S2213-2600(14) 70001-3

25. Bozdogan H. Model selection and Akaike's information criterion (AIC): the general theory and its analytical extensions. Psychometrika. 1987;52:345-370. doi:10.1007/BF02294361

26. McGarvey L, Morice AH, Smith JA, et al. Effect of aclidinium bromide on cough and sputum symptoms in moderate-to-severe COPD in three phase III trials. BMJ Open Respir Res. 2016;3: e000148. doi:10.1136/bmjresp-2016-000148

27. Tsiligianni I, Metting E, van der Molen T, Chavannes N, Kocks J. Morning and night symptoms in primary care COPD patients: a cross-sectional and longitudinal study. An UNLOCK study from the IPCRG. NPJ Prim Care Respir Med. 2016;26:16040. doi:10.1038/ npjpcrm.2016.40

28. Lu M, Wang X, Cai B, et al. Perception of circadian variation of symptoms in Chinese patients with chronic obstructive pulmonary disease. J Thorac Dis. 2017;9:3888-3895. doi:10.21037/jtd

29. Kourlaba G, Hillas G, Vassilakopoulos T, Maniadakis N. The disease burden of chronic obstructive pulmonary disease in Greece. Int J Chron Obstruct Pulmon Dis. 2016;11:2179-2189. doi:10.2147/ COPD

30. Muñoz A, Small M, Wood R, Ribera A, Nuevo J. The impacts of morning, daytime, and nighttime symptoms on disease burden in real-world patients with COPD. Int J Chron Obstruct Pulmon Dis. 2018;13:1557-1568. doi:10.2147/COPD

31. Stephenson JJ, Cai Q, Mocarski M, Tan H, Doshi JA, Sullivan SD. Impact and factors associated with nighttime and early morning symptoms among patients with chronic obstructive pulmonary disease. Int J Chron Obstruct Pulmon Dis. 2015;10:577-586. doi:10.2147/COPD

32. Miravitlles M, Ribera A. Understanding the impact of symptoms on the burden of COPD. Respir Res. 2017;18:67. doi:10.1186/s12931017-0548-3

33. Chapman KR, Beck E, Alcaide D, Garcia Gil E. Overall and cardiovascular safety of aclidinium bromide in patients with COPD: a pooled analysis of six phase III, placebo-controlled, randomized studies. Chronic Obstr Pulm Dis. 2015;3:435-445. doi:10.15326/ jcopdf.3.1.2015.0148

International Journal of Chronic Obstructive Pulmonary Disease

\section{Publish your work in this journal}

The International Journal of COPD is an international, peer-reviewed journal of therapeutics and pharmacology focusing on concise rapid reporting of clinical studies and reviews in COPD. Special focus is given to the pathophysiological processes underlying the disease, intervention programs, patient focused education, and self management protocols. This journal is indexed on PubMed Central, MedLine and CAS. The manuscript management system is completely online and includes a very quick and fair peer-review system, which is all easy to use. Visit http://www.dovepress.com/testimonials.php to read real quotes from published authors. 